\title{
Emergence of Homo spiritualis: Of Essential Requirements - Faith, Devotion and Love: Deep Science of their Psychoneurobiology
}

\author{
Mukhopadhyay AK*
}

Department of Laboratory Medicine, All India Institute of Medical Science, New Delhi, India

${ }^{*}$ Corresponding author: Mukhopadhyay AK, Department of Laboratory Medicine, All India Institute of Medical Science, New Delhi, India, Tel: +91 11 79600585; E-mail:mukhoak1953@gmail.com

Received date: October 15, 2019; Accepted date: November 11, 2019; Published date: November 18, 2019

Copyright: (c) 2019 Mukhopadhyay AK. This is an open-access article distributed under the terms of the Creative Commons Attribution License, which permits unrestricted use, distribution, and reproduction in any medium, provided the original author and source are credited.

Citation: Mukhopadhyay AK (2019) Emergence of Homo spiritualis Of Essential Requirements - Faith, Devotion and Love: Deep Science of their Psychoneurobiology. Clin Psychiatry Vol.5 No.2:62.

\section{Abstract}

On the landscape of human possibilities, consciousnessrooted futurologists predicts emergence of Homo spiritualis from the present Homo sapiens. On this passage, to tide over different grades of uncertainties cultivation of Faith, Devotion and Love is felt essential. The deep science in psychology, biology and neurology has been discussed while cultivating such qualities in life. The beneficial spin offs from such perspective are new ideas and several research questions, addressing of which might help to extend the vertical depth and horizon of science.

\section{Keywords}

Homo spiritualis; Devotion; Love; Faith; Consciousness

\section{Introduction}

About sixty years back Science published the "Doomsday Equation" [1], which predicts that on Friday of November 13, 2026, the world population is going to be infinite and human survival would be difficult to continue. Similar kind of gloomy picture is also painted on the future of humanity by several intellectuals such as historian Francis Fukuyama in The End of History and the Last Man, John Horgan, the editor of Scientific American in, The End of Science: Facing the Limits of Knowledge in the Twilight of the Scientific Age, Richard Dawkins in The God Delusion, Christopher Hitchens in, God is Not Great: How Religion Poisons Everything etc. Spirituallyinclined scientists (for example, Alfred Russell Wallace [2], cofounder of the theory of evolution along with Darwin, French palaeontologist Pierre Teilhard de Chardin) and the scienceeducated-spiritualists (for example, John Hagelin, Michael Cremo [3], and several others who could be found participating in SAND, https://www.scienceandnonduality.com conference), however, have a different view. They predict for a brighter future for present Homo sapiens.
The Gene-rooted futurologists predict emergence of Homo optimum, human species free from any genetic disease. Information-rooted futurologists predict multiple emergence such as Homo cyberneticus, Homo hybridus, Homo machinus etc. Homo spiritualis is the prediction of consciousness-rooted scientists. In the year 2010 in Motilal Nehru Institute of Technology, Allahabad, India, author presented a paper in Science and Spiritual Quest titled, "On the Landscape of Human Possibilities. Tendencies of Homo Sapiens to Become Homo Spiritualis" [4]. Sapiens means knowing and the next species will be knowing more. Therefore, the organ of cognition, the brain, is in focus during this emergence. The basis of assertion on this emergences are (a) reconstruction of the past, and (b) projection on the basis of existing knowledge. The Time-frame has been set about three hundred years. Besides extraordinary existence of prophets and sadgurus, possible examples of such emergent has been drawn from four groups of people who exemplify these tendencies; (i) personalities who could be designated as long term visionary, (ii) creative people with impeccable axiological integrity (iii) meditators who have the experience of going into samadhi state repetitively and coming successfully out of the state with freshening newness, and finally, (iv) the group of people, not lost in the crowds, who have had the experience of survival from a protracted death in hospital bed/natural calamity/war disaster, and at present living their life with a changed vision, which are characteristics of what we call Homo spiritualis.

\section{Characteristics of Homo spiritualis}

Global crisis evokes a spiritual responsibility. And, spirituality needs a science. Replacing God, Francis Crick and Christof Koch brought a respectable position of consciousness in biological science decades after quantum physicists discovered ineliminable role of human consciousness in observation. Like One God having numerous tinctorial shades and heights, plurality in singular consciousness has been brought by imposition of the organ what we call brain. The view which gradually has developed is as follows. Science investigates nature, spiritualism is investigation of nature of consciousness and mysticism is investigation of unconditional consciousness. 
We define Homo spiritualis as those who dwell in the nature of consciousness, whose nature is in complete tune with Mother Nature. During such investigation of the nature of consciousness, the scientists as well as initiated spiritualists themselves emerge as Homo spiritualis.

The emergent has an open-ended laudable attitude and multifaceted thinking process. They are resilient, perseverant, innovative and exhibit an amazing skill of moving beyond failure and success to the next what they charter to do. In personal life, they live a transparent life full of compassion and empathy. They are in peace with themselves and emanate peace in the environment. They are stress-buster. By their mere presence, they eliminate stress from the mind of the people. Without getting into conflict, they take the organisation to a higher level.

\section{Different Terminology for the Emergent}

Shall we call the emergent a Super human, Metahuman, Divine being, Supracortical being or Homo spiritualis? Super human is a layman's term but popular in the West also meaning differently to different people. However, the emphasis is on their extraordinary mental acumen, may be in a specified direction. Deepak Chopra calls them Metahuman [5]. Accomplished spiritualists such as Sri Aurobindo, and author's Gurudev describe them as Divine being. In the language of evolutionary scientists the emergent has been called Homo spiritualis.

In author's earlier work [6] this emergence has been described as an emergence from a brainstem being, limbic being and cortical being as cortico-supracortical being, supracortical being, supracortical godhead and supracortical autonomy. Last three labels are consistent with alternate terminology such as saint, sage and siddha respectively, which is in concurrence with another terminology of brahamachari, swami and paramahansa respectively as described in various Hindu sects.

\section{Call to Participate in this Emergence!}

Sir Arthur Eddington said, "Our story of evolution ended with a stirring in the brain-organ of the latest of Nature's experiments, but that stirring of consciousness transmutes the whole story and gives meaning to its symbolism. Symbolically, it is the end, but looking behind the symbolism, it is the beginning."

The critical mass of population looking behind such symbolism has been gaining momentum especially in the West by mass sensitization of the younger generation by the work of Deepak Chopra, annual conference Towards a Science for Consciousness since 1994 (https://en.wikipedia.org/wiki/ Toward_a_Science_of_Consciousness), annual SAND (Science and Non Duality, https://www.scienceandnonduality.com) conference, annual meetings by Scientific and Medical Network, UK and their Galileo Commission (https:// www.galileocommission.org) for extending the horizon of science, annual Science and Spiritual Quests organised by Bhaktivedanta Institute, besides the preaching and teaching of numerous masters of different spirituality. Further, there are thousands of scientists and spiritualists communicating in Science and the Scientist Forum (https:// www.scienceandscientist.org) through sadhu sanga Google group.

\section{Some predisposing factors might support the emergence}

There are some predisposing factors for such emergence such as genetic propensity, environmental factors, deep cultural association with like-minded friends, philosophers and guide.

\section{Some precipitating factors often help the candidate to join this emergence}

The person/scientist might deliberately choose the course by listening to the non-local call, being often guided by an accomplished emergent to take such course, or might be compelled to enter this course while tossed in either-life-ordeath situation during existential crisis.

The first step: The first step is simple. Oh man! Raise your head. Just look up! Come out of the agenda run by your conditioned existence of Ego and follow the agenda of the Infinity/Whole/Unconditional Consciousness. Choose any of the three you are comfortable with. Start from the Infinity and your finites will be taken care of. All of us do it once in a while but practice it regularly, dwell in it. The Infinity will descend in you and would organize your finites.

Following is the statement of author's call to the scientists for participating in this emergence.

"Come out of your brain and start looking at the brain from supracortical position. Start seeing through the boundary of the universe, across the multiverse, and begin to understand how Infinite becomes finite. While flirting with quantum physics, instead of asking question such as quo vadis quantum mechanics, start asking unde venis quantum mechanics? Penetrate through quantum void into the sub-quantum nest of nature. Instead of wandering on the flatland of science assuming tortuosity for complexity, look at the verticality, deep up and down, for the source field of the events and phenomenon on this flatland. Catch hold of a complicated signal and start following it towards its meanings, then the source of the meaning and so on........"

More specifically, the call is for doing a deep science: The call is for doing a Deep Science. In fact, this is deeper than what we mean by DeepMind and Deep Learning in Artificial intelligence.

- The first step for neuroscientist is to come out of the brain and then to look at the brain from supracortical position.

- The first step for information scientist is to understand the mechanism how signal is converted into information and 
how information is brought down as signal, to look at this operation and to catch up with the Mind.

- The first step for a conventional scientist is to stop wandering tortuously on the flatland of science with a false assumption of investigating complexity, and to identify and look into the Constants of Science which have been preventing penetrating into vertical depth of nature!

- The first step for quantum physicists is to stop flirting with, and leave fantasizing quantum mechanics and rather penetrate through quantum void to sub-quantum nest of nature at sub-Planckian scale to catch up with the issue of unde venis quantum mechanics?

- The first step for cosmologist and astrophysicist is to cross the boundary of the universe and get into the realm of multiple universe(s) in the systems science of the Multiversity to find out how the systems of Multiverse manage our universe!

\section{Further Scope for Homo spiritualis}

The new emerging species, Homo spiritualis, occupies a unique position in developing the science for consciousness, that is to align present science completely within the nests of nature- consciousness. In the process, systems view of science spontaneously surfaces. They find, it is possible to relate systems physics with systems psychology, systems biology with systems cosmology. This new science grows in concurrence with the growth of humanity and human spirit (consciousness). The humanity flourishes at ease with scientific and spiritual pursuits.

\section{Individual's assets as required for participating in this process of emergence}

The present humanity is poised at the threshold of a new formation when the brain-bound consciousness (brain-trapped consciousness, brain-confined consciousness, brain-encased consciousness) senses the existence of brain-independent consciousness. A system that can act locally and has the ability to communicate non-locally reserves chances to evolve. At this point, we may make it clear that our present brain is an incompletely evolved organ. While the other organs of the body have nearly accomplished the evolutionary goal, the brain is yet to achieve this. The purpose of evolution of the organ brain is stated to unify consciousness within and consciousness without. Having done this the brain becomes transmissive for manifestation of Mother natureConsciousness.

What are the core assets as required out of present Homo sapiens for this process of emergence? Three core assets as required for this emergence are Faith, Devotion and Love; each of which is described below.

Faith: When uncertainty knocks at our door, we (Self) must open it with faith. Having done, we are surprised to see that nothing is there! Faith is required to wade through this nothingness. Uncertainty is of various degrees at different depths of nature: (i) uncertainty of classical level while waiting for either yes or no, head or tail of a coin; (ii) uncertainty between related properties such as space and time of the same identity. This is organizational uncertainty at the microscopic level, quantum uncertainty of Heisenberg; (iii) existential uncertainty as observed between present existence and no existence as observed at the level of the blackhole; and (iv) uncertainty as observed between no existence and a new existence, as observed at the edge of the universe, between universe and the multiverse.

Uncertainty reduction is largely measurable and therefore falls within the ambit of present science. Investigation of uncertainty is, in fact, an essential frontier of Deep Science. Uncertainty is ameliorated by contextual information of the whole. Signal-information has a vertical hierarchical existence in nature and such investigation extends the vertical depth of science.

What is popularly known as belief systems is either evidence-based or faith-based. Science is evidence-based. Religion is faith-based. Spiritualism is evidence-based, where evidence are of different quality and kind as compared to those in science.

Max Planck said, "Anybody who has been seriously engaged in scientific work of any kind realizes that over the entrance of the gates to the temple of science are written the words: ye must have faith. It is a quality which scientists cannot dispense with....." Stanley Fish concurs, "Science requires faith too before it can have reasons."

Assumptions in science, however, could not be said faithbased. Faith in some yet-to- be proved assumptions extends over a limited scale and gets over with appearance of evidence. Science is all about relentless enquiry with its methods, logic, initial assumption followed by verification and finally securing evidence. Finally, science speaks in common universal language.

Faith as in doing science is therefore different from faith as in religion since in the former the initial assumption is subject to change. In religion it persists, hard to change and spreads horizontally to generate different "Faith Community", and so for their unification there are interfaith meetings. Scientific establishment does not represent one single community as in religion. (Many have started thinking they do, since the time there is replacement of passionate disinterested search for truth in science by scientists captured by vested interest). In pursuit of spirituality, the initial assumptions are subject to transformation throughout the process extended over the entire vertical depth. Relentless questioning of established view is characteristic of both scientific and spiritual enquiry. Spiritualists explore the nature of consciousness and therefore, spiritual enquiry has all attributes of scientific enquiry but added feature in spiritual enquiry is its vertical depth. However, this has been noted that reasons obtained through scientific enquiry hardly can change the core belief systems [7] while reasons obtained in pursuit of spiritualism is capable of changing the core belief system.

Faith in self, and faith in infinity/whole/unconditional consciousness: An agnostic is indifferent to existence of God. An atheist believes in existence of God. An atheist does not 
believe in existence of God. All these are not much relevant in science of spirituality, when consciousness is accepted as last frontier of science. To start investigation and exploration of nature, of natural laws and principles, of relationship between self and nature, one has to have faith in self (the explorer, the subject), and have faith in nature-consciousness (the object of exploration), the nature as a whole, the infinity the nature as intellectually comprehensible (for example, the systems of multiple universe, the Multiversity), or the unconditional consciousness, or in the emergent who has already personified such nature-consciousness! While faith is operated by self, and is mainly bottom-up, during devotion there is top-down guidance of the bottom-up, aspirations.

Devotion: Growing pole of faith culminates in devotion. The goal in which faith has been reposed is crystallized as someone/something/specific purpose. While in faith the objective entity is yet-to-be seen, devotion comes following emergence of distinct duality; me and someone/something/ specific purpose. And, then comes the feeling of being loyal, dedicated and committed to someone, something, or the specified purpose. Once committed, there follows investment of time, health, wealth, effort (thoughts, language and behaviour) into it.

Examine the devotional attitude of Francis Collins, Director of the National Human Genome Research Institute, when he says, "For me the experience of sequencing the human genome, and uncovering this most remarkable of all texts, was both a stunning scientific achievement and an occasion of worship" [8]. Also examine how Maria Mitchell (1818-1889), American astronomer used to look at the nature when she says, "Every formula which expresses a law of nature is a hymn of praise of God." The self and life of such scientists are full of faith and devotion.

While faith involves self and its logic systems, devotion involves "life"-systems of the subject, the explorer. There is channelized emotion to strengthen and enrich faith. Devotion is an expression of inspired "life". Life style in its entirety is geared up for serving the committed purpose with no eyes on achievements or on the gamut of contribution.

In cell biology, we find commitment of stem cell towards development of the progenitor cells. This kind of devotion manifested behaviourally as commitment is to serve a specific purpose in concurrence with the environmental/situational need. The commitment is rooted in the genes. However, the decision comes from not genes but from a deeper plane. It involves life processes which regulates genes. However, there is a fusion of bottom-up aspiration of the requirements with top-down decision of the governance.

In spiritual parlance, the devotion means commitment for the whole/the Infinity/the Multiversity/Unconditional consciousness. In devotion, top-down governance of the Multiversity concurs with the bottom-up aspiration of the world. Top-down governance of the Sadguru/Master/ Supracortical Autonomy concurs with the bottom-up aspiration of the Aspirant/disciple/student. Non-local communication concurs with local operation of the systems. In the language of evolution, in a newly set Darwinian race, Dawkinian 'memes' (Richard Dawkins who coined the term memes as unit of thought which is transmissible) start influencing Gouldian (Stephen J Gould, the evolutionary biologist) genes! Epigenetic mechanisms override several genetic process. Histone asserts its wisdom on the coiled DNA within the nucleus of the cell.

In devotion, the seeker spontaneously assumes various poise, postures, asana! Postures have roles in the quality of cognition. Both cerebral cortex and cerebellar cortex are rich in astrocytes which form tripartite synapse with neurons and form the cognitive apparatus. Cerebellum not only does quality control of posture as per established scientific notion, the major part (about $80 \%$ ) of its functions is quality control of thoughts, as revealed in a recent paper published in journal Neuron [9].

In the phase of devotion, every breath of "life" is dedicated, committed towards the purpose, the goal. As a result, there is percussion on genes. How? Devotion changes the breathing pattern of the subject and there happens spontaneous Pranayam. Oxygen-sensor mechanism [10-12] within the cell (VHL genes-Hypoxia Inducible Factor as modified by prolyl hydroxylase-Ubiquitin) becomes active for adaptation of the cell biology with the pressing memetic need of the being. During such tendencies for neoformation, cheers for Evo-Devo excitement, there are all possibilities of turning on certain developmental regulatory genes, [13], which are usually active during embryogenesis when ontogeny repeats or does not repeat but creates phylogeny. Cultivating devotion is thus very important for self-directed genetic transformation.

By induction of operation of faith, gene-directed biological transformation becomes what is called self-directed biological transformation [14]. With initiation of operation of devotion, self-directed biological transformation turns into life-directed biological transformation, when the life of the subject remains tuned with Mother Nature. Unassuming personality of the devoted individual is a reflection in the behaviour of his brain near to zero-point energy state, when there is perfect homeostasis of visible energy and dark energy [15] in biological homeostasis. Devotion matures with cultivation of hundred per cent obedience to the Whole/Infinity/the Multiversity.

Devotion is melting Love. Intervention by consciousness in the life-processes of the committed devotee turns devotion into love. Inexhaustible dark energy starts manifesting as visible energy within the finite limits of the neurobiology.

Love: Carl Sagan said, "For small creatures such as we, the vastness is bearable only through love." What is this Love? Melting love is devotion and crystallized devotion is Love. The details of getting into the love is not known but intervention of consciousness seems a must in the process. The author has hypothesized love as behavioral manifestation of supracortical consciousness. As supracortical consciousness is inexhaustible so love could be inexhaustible too, of course within cortical limits! Love could be visualized in behavior as sacrifice for the beloved. Sacrifice is observable and could also be measured. 
This suggests the neural basis of love. Love also has a genetic basis. One cannot love music or a flower unless one has genes for it. Love could 'turn on' the genes. Molecular signaling for gene expression could be influenced by molecular changes brought about by this enacted emotion and feeling, which has little expectation and practically no limitation. Love is often confused with lust when one looks at only on the gonadal basis of love. To distinguish, lust serves the person, himself/ herself. Love serves the beloved. Love begets peace. Lust begets restlessness and turbulence. Many a times love and lust get messed up. Then one needs to separate the grain from the husk, the substance from the form, a difficult task but essential for the emergence.

While faith operates in guidance of self, and is mainly bottom-up, and in devotion there is top-down guidance of the bottom-up aspirations of self by "life", in love there is complete concurrence, synchronization of the both bottom-up and top-down processes resulting in resonance after resonance, a behavioural manifestation of the captivating power of consciousness.

Cultivation of Faith Devotion and Love: Faith can be cultivated, and it is worth cultivating it. Faith grows into devotion, which in turn, crystallizes into love. Every step and the process followed, demands cultivation. There are rituals, exercises in every culture, to be initiated quietly by self in apparent silence of cause, in apparent stillness of time, in emptiness of space when there is apparently nothingness in life.

Spirituality always has a cosmological connotation. To speak in cosmological perspectives, interstellar void could be circumvented by faith, intergalactic void by devotion and interuniversal void is conquered by love!

Let me quote from my own poetry

"Not all silence is swallowing up of noise,

Not all stillness is engulfment of time,

Not all emptiness is the subatomic void,

Not all nothingness is absence of rhyme."

"There is silence which broods Cause,

There is stillness, generating time with pause

There is void from which the universe is born,
Deep psychology of faith, devotion and love: It is said, "scientific analysis of faith sounds like an oxymoron" [16]. However, for the emerging Worldview, love, devotion and faith are behavioural manifestations of a complex interactions of three autonomous potent causal agents of the systems psyche [17] namely consciousness, self and life. Mind has very little role in their origin and growth.

It is self, which takes the first initiative in this endearing process, helps to bring rationale in apparently irrationallooking faith. Self's tangled partner, the life, joins the trip in due course of time, following emergence of a distinct duality, and contributes for amalgamating feelings and emotion with faith, which eventually grows into devotion. Consciousness supports this initiative, development and growth. Then follows another important phenomenon, when inside becoming out and outside becoming in. By this process, consciousness gets the appropriate occasion to intervene and as a result the feeling of affection is enacted as expression of love in the behaviour.

Deep neurology of faith, devotion and love: The complex psychology of faith devotion and love has been described. What about their neurological root? Systems psyche operates as the interphase between brain-bound and brainindependent consciousness [18]. The neural basis of love works when brain-independent consciousness operates through cerebral cortical machinery. Cerebral cortex is made of six neural layers. There exists an electrophysiological watershed between upper three and lower three layers. Routine cortical work, which is mostly cognitive reflex, is managed by lower three layer's activity. Removal of upper three layers does not change brain's EEG pattern except delta waves as seen in deep sleep. During growth of faith, there is anchoring of third cortical layer neurons with the modular cortex of lower three layers. Development of devotion leads to anchorage of both third and second cortical layers into the modular cortex. The culmination happens when the top most first cortical layer neurons also get anchored, along with already anchored second and third layer neurons with the neurons of the modular cortex. In faith devotion and love, the neural mechanism operates horizontally as bi-hemispheric, along with vertical synchronization of the neuraxis of brain stem, diencephalon and the cortex, culminating into effect by global supracortico-cortical synchronization during Love (Figure 1).

Ananda shines when nothingness is torn. 


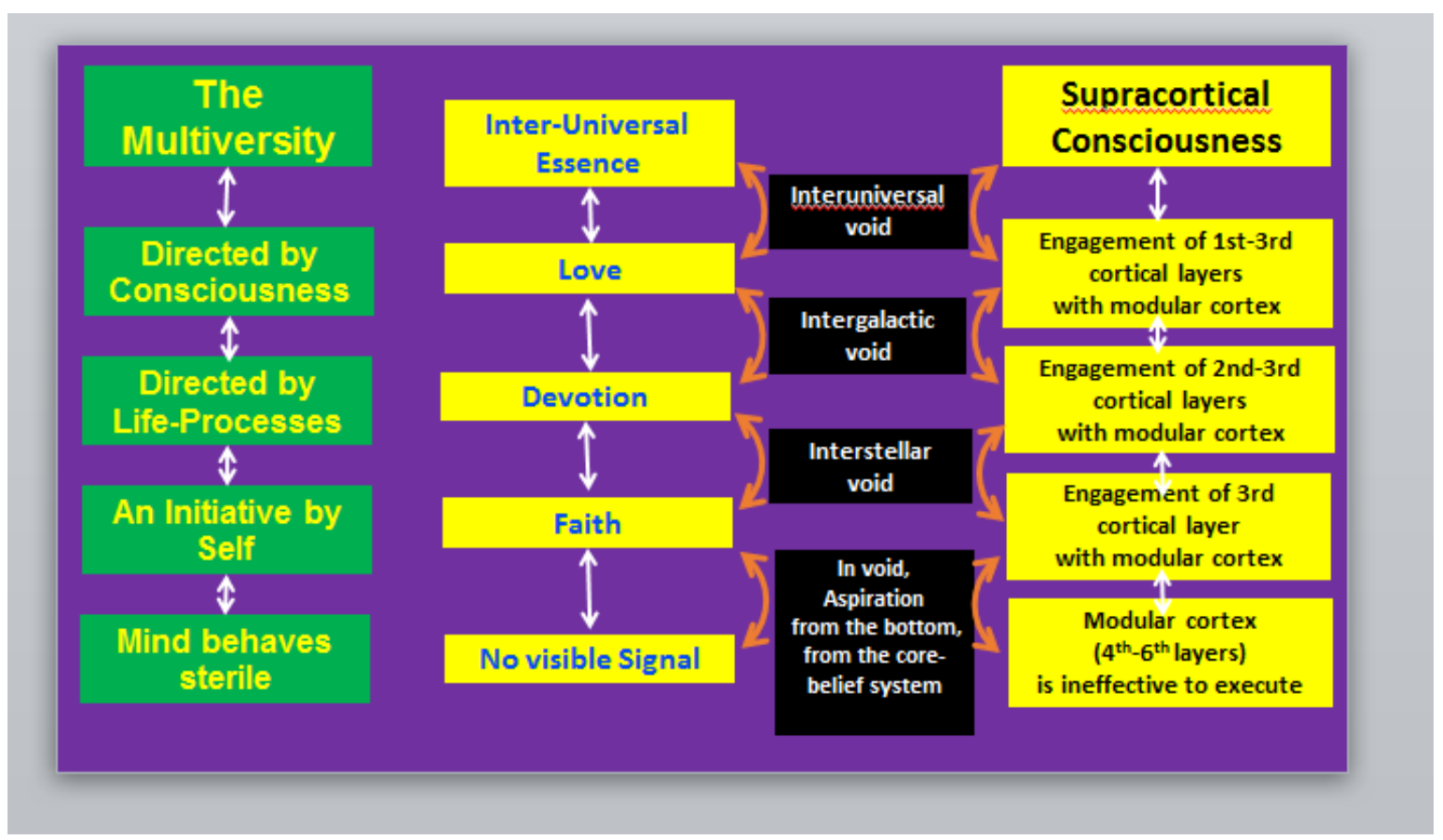

Figure 1: Reading it from the bottom the figure shows in absence any visible signal and when mind is sterile and modular cortex is ineffective to execute, how Faith develops from the core-belief system by initiative of self to help tide over the first grade of uncertainty. Next up is the role of Devotion directed by life processes and engagement of supra-modular neurons with those in the modular cortex to tide over the second grade of uncertainty. Finally Love, directed by Consciousness, with total engagement of supra-modular cortex with modular cortex help to tide over the uncertainty at the edge of the universe.

\section{The Brain of a Brain}

We cannot explain acquisition of the new faculty of knowing and feeling as observed in the Homo spiritualis by the known parameters as used to measure evolution of the brain in terms of its perceptual, receptual (ability to categorize) and conceptual ability. We expect to find in this new emergence, formation of a new structure, a new brain, the brain of a brain, which as the organ of new faculty of knowing and feeling is responsible for (i) integration of sensory, extrasensory and nonsensory perceptions (ii) integration of surface, elementary and depth phenomenology and (iii) integration of cognitive, psychomotor and affective brains. The urgency for speciation calls on the special property of neural plasticity of the brain. In response to this clarion call for a new speciation three groups of cortical neurons are called upon to form a new centre. (i) Cortical neurons which have expertise in non-local communication through supracortical route are the first ones to respond. (ii) There is abundance of mirror-neurons in cerebral cortex, which are supposed to have contributed a lot in the development and spread of culture but look like intelligent dwarfs in individual capacity but long for a new informational integration and join the first group in formation of a higher brain centre. For a development, which is so radical, one may think of (iii) a possible contribution of stem cells from the 'brain marrow' [19] towards this realization of a new structure over the vortex of the cerebral hemispheres, as the brain of a brain! The sine-qua-non of emergence of Homo spiritualis is development of the brain of a brain [20].

\section{Concluding Remarks and Perspectives}

On the landscape of human possibilities this paper presents the essential requirements for emergence of Homo spiritualis from Homo sapience. The humanity has been wading through various grades of uncertainties and the weapons to be sharpened to tide over those uncertainties are Faith Devotion and Love. The psychology, neurology and biology of cultivation of faith devotion and love have been discussed. This is the humble part of the message in this paper. On the other side the paper challenges the status quo in neuroscience, psychology and cell biology, takes a seismic leap in Deep Science with innovative ideas, assumptions and research questions. At the end, the paper offers a platform for multidisciplinary investigations in evolution, cell biology, psychology, neurology and spirituality.

\section{References}

1. Robertson JS, Bond VP, Cronkite EP, William E, Hutton WE, et al. (1961) Doomsday. Science, 133:936-946.

2. Wallace AR (1892) Spiritualism. Chamber's Encyclopedia, Vol. 9. William and Robert Chambers, Ltd, London.

3. Cremo MA, Thompson RL (1998) Forbidden Archaeology, The Hidden History of Human Race. Bhaktivedanta Book Publishing Inc. Los Angles, Sydney, Stockholm, Bombay.

4. https://akmukhopadhyayconsciousness.com/pdf/theLandscape-of-Human-Possibilities.pdf 
5. Chopra D (2019) Metahuman. Unleashing your Infinite Potential. Harmony (part of publisher Penguin Random House), New York.

6. https://akmukhopadhyayconsciousness.com/pdf/The-Self-andits-Memes-and-Genes.pdf

7. Ludden D (2017) Does Science Require a Leap of Faith?

8. Collins $F$ (2006) The Language of God: A Scientist presents Evidence for Belief. Free Press (Simon \& Schuster, Inc.), New York.

9. Marek S, Siegel JS, Gordon EM, Raut RV, Gratton C, et al. (2018) Spatial and Temporal Organization of the Individual Human Cerebellum. Neuron.

10. Semenza, GL (1999) Regulation of mammalian O2 homeostasis by hypoxia-inducible factor Annu Rev Cell Dev Biol. 15:551-578.

11. Ivan M, Kondo K, Yang H, Kim W, Valiando J, et al. (2001) HIFalpha targeted for VHL-mediated destruction by proline hydroxylation: Implications for $\mathrm{O} 2$ sensing. Science, 292:464-468.

12. Jaakkola P, Mole DR, Tian YM, Wilson MI, Gielbert J, et al. (2001) Targeting of HIF-alpha to the von Hippel-Lindau ubiquitylation complex by O2-regulated prolyl hydroxylation. Science, 292:468-472.

13. Gilbert SF (2003) Developmental Mechanisms of Evolutionary changes. Developmental Biology, Sinauer Associates, Sunderland, MA.
14. Peterson CT, Lucas J, John-Williams LS, Thompson JW, Moseley MA, et al. (2016) Identification of Altered Metabolomic Profiles Following a Panchakarma-based Ayurvedic Intervention in Healthy Subjects: The Self-Directed Biological Transformation Initiative (SBTI) Sci. Rep. 6: 32609.

15. Mukhopadhyay AK (2019) Zero-Point Energy State of the Brain. Arch Neurol \& Neurosci. 2: 000547.

16. David H (2009) The Science of Faith. https:// www.newstatesman.com/blogs/the-faith-column/2009/02/ religious-concepts-science

17. Mukhopadhyay AK (2016) Systems Psyche: Its Structure, Operation and Possible Molecular Links. Psychol Behav Sci Int J 1: 555: 565.

18. Mukhopadhyay AK (2016) Systems-bound and Systemsindependent Consciousness Complex Inter-phase in between: From Narrative to Science. Psychol Behav Sci Int J 1: 555: 562.

19. Bjornson $C R$, Rietze RL, Reynolds BA, Magli MC, Vescovi AL (1999) Turning brain into blood: a hemopoietic fate adopted by adult neural stem cell in vivo. Science 283: 534-537.

20. Mukhopadhyay AK (2000) The Brain of a Brain, The Sine-quanon of the New Human Species emerging on this Earth. The Millennium Bridge, Conscious Publications, New Delhi: 136-152. 